\title{
Improving Maternal and Child Health in India: Evaluating Demand and Supply Side Strategies (IMATCHINE): Pre-Analysis Plan
}

\section{December 2013}

This document outlines the analysis plan for "Improving Maternal and Child Health in India: Evaluating Demand and Supply Side Strategies" (IMATCHINE), a randomized controlled trial of performance incentive contracts for obstetric care providers based on inputs or outputs. The document provides a pre-specified methodology and plan for analyzing the results of the experiment.

\section{Study Overview}

"Improving Maternal and Child Health in India: Evaluating Demand and Supply Side Strategies" (IMATCHINE) is a randomized controlled experiment designed to test the effectiveness of supply-side incentives (pay-for-performance) for private obstetric care providers in rural Karnataka, India. In particular, we assess the differential impact of incentive contracts that reward providers based on quality of care ("inputs") and those that reward providers for favorable health outcomes ("outputs") on provider behavior, quality of care, and maternal and infant health outcomes. In addition, we also aim to qualitatively understand how providers respond to the presence of these incentives.

\section{Experimental Design}

The randomized experiment consists of two orthogonal treatment arms and a control arm. Eligible $^{1}$ rural private obstetric providers in were randomly assigned to one of the three arms. Below we first describe each of the three arms, and then provide further details about the intervention.

\section{ARM 1: “Outputs” Contract}

Providers in this arm are offered a contract that provides financial rewards based on the incidence of four adverse maternal and neonatal health outcomes among their patients: post-partum hemorrhage, pre-eclampsia, sepsis, and neonatal mortality. ${ }^{2}$ For each maternal health outcome (incidence of outcome $i=x_{i}$ ) the reward payment $P\left(x_{i}\right)$ is structured as a decreasing linear function of incidence in the provider's patient population, starting at a maximum threshold $\bar{x}_{i}$ percent incidence:

\footnotetext{
${ }^{1}$ See "Selection of Providers into the Study" below for a more detailed explanation of how providers were judged to be eligible or not.

${ }^{2}$ See Appendix for a detailed explanation of how outputs are measured.
} 


$$
P\left(x_{i}\right)=\left\{\begin{array}{cl}
\alpha_{i}\left(\bar{x}_{i}-x_{i}\right), & x_{i} \leq \bar{x}_{i} \\
0, & x_{i}>\bar{x}_{i}
\end{array}\right.
$$

$\alpha_{i}$ is predetermined based on the projected range of improvements and budget considerations, and $\bar{x}_{i}$ is set at projected pre-intervention average rates. Pre-intervention average rates for each of the three adverse maternal health outcomes were determined using existing data from government surveys and calibrated through piloting with doctors in Karnataka and Delhi to ensure that they were locally appropriate. For neonatal death, providers are offered a flat reward amount for achieving zero neonatal deaths in their patient population. Each provider's total reward payment is the sum of rewards earned for each of the four adverse health outcomes.

For example, pre-intervention rates of post-partum hemorrhage (PPH) were estimated at 35 percent $\left(\bar{x}_{P P H}=35\right)$ in the study area. Providers earn $\alpha_{P P H}=$ Rs. 850 (equivalent to about $\$ 17$ at the time of the contract) for every percentage point below 35 percent incidence of $\mathrm{PPH}$ in their patient population. For example, if the rate of PPH in their patient population was 25 percent, they would earn $\$ 170$, and if they were able to completely eliminate PPH in their patient population, they would earn \$595.

Each provider is instructed that outcomes will be measured through household surveys of patients who come to her for care over the following year. At the end of this period, providers in the output group are given a one-time reward payment based on their performance on the four adverse health outcomes. To minimize the likelihood that providers selectively refuse high-risk patients, the contract contains a clause that if evidence of refusal to provide care is detected in the local population, the contract will be voided and the provider will be ineligible for the reward payment.

\section{ARM 2: “Inputs" Contract}

Providers in this arm are offered a contract that provides financial rewards based on healthcare inputs provided to their patients. These inputs are based on recommendations in the current World Health Organization (WHO) guidelines for basic obstetric care that were distributed to all providers in the study when they agreed to participate. ${ }^{3}$ Input quality is measured separately in the five domains: Pregnancy Care, Childbirth Care, Postnatal Maternal Care, Newborn Care, and Postnatal Newborn Care. ${ }^{4}$ For each domain of care (performance in domain $i=x_{i}$ ) the reward payment $P\left(x_{i}\right)$ is structured as an increasing linear function of the quality level achieved in the provider's patient population, starting at a minimum threshold performance level $\underline{x}_{i} \%$ :

$$
P\left(x_{i}\right)=\left\{\begin{array}{cl}
\alpha_{i}\left(x_{i}-\underline{x}_{i}\right), & x_{i} \geq \underline{x}_{i} \\
0, & x_{i}<\underline{x}_{i}
\end{array}\right.
$$

\footnotetext{
3 "WHO Recommended Interventions for Improving Maternal and Newborn Health."

${ }^{4}$ See Appendix for a detailed explanation of how inputs are measured.
} 
$\alpha_{i}$ is predetermined based on the projected range of improvements and budget considerations, and $\underline{x}_{i}$ is set at projected pre-intervention average rates. Pre-intervention average rates for each of the five domains of care were determined using existing data from government surveys and calibrated through piloting with doctors in Karnataka and Delhi to ensure that they were locally appropriate. Each provider's total reward payment is the sum of rewards earned for their performance in each of the five domains of care.

For example, pre-intervention coverage of the inputs in the Childbirth Care domain was estimated at about 65 percent $\left(\underline{x}_{\text {Childbirth Care }}=65\right)$ in the study area. Providers earn $\alpha_{\text {Childbirth Care }}=$ Rs. 750 (equivalent to about $\$ 15$ at the time of the contract) for every percentage point in coverage of these inputs above 65 percent. For example, if the coverage of inputs in the Childbirth Care domain in the provider's patient population was 75 percent, she would earn $\$ 150$, and if she was able to provide care satisfying all the WHO standards for all patients, she would earn $\$ 525$.

Each provider is instructed that input quality will be measured through household surveys of patients who come to her for care over the following year. At the end of this period, providers in the inputs group are given a one-time reward payment based on their performance in the five domains of care. To minimize the likelihood that providers selectively refuse high-risk patients, the contract contains a clause that if evidence of refusal to provide care is detected in the local population, the contract will be voided and the provider will be ineligible for the reward payment.

\section{ARM 3: Control Contract}

Providers in the control arm are offered a contract to participate in the study, but no incentive payments. They are made aware of input and output categories and offered the same information that providers in treatment arms receive (see "Intervention Design" for more details).

\section{Incentive Payment Amounts Calculation}

Incentive payment amounts $\left(\alpha_{i}\right)$ were calculated based on budget considerations and the projected range of performance changes. Specifically, we anticipated a maximum average performance of $90 \%$ for inputs in each of the five domains and a minimum average rate of $5 \%$ for outcomes in the three maternal morbidity categories. We allocated a fixed Rs. 15,000 for zero neonatal deaths in the provider's patient population. Given these projected performance outcomes in both treatment groups, the total quantity budgeted for rewards was then divided between outputs and inputs. This means that the maximum reward payment in each of the treatment groups is approximately the same and that if all providers included in the experiment achieved our anticipated highest performance on average, no money would be left on the table.

Within each treatment group, the money allocated for rewards was evenly divided among each category (with the exception of neonatal mortality, which was given a fixed reward intended to be close to the amount paid out in other categories). As a result, incentive payment amounts are mechanically higher or lower depending on how high or low 
baseline rates are. Payments for each higher percentage point in inputs performance range from Rs. 450 to Rs. 3,700, and for each lower percentage point in outputs performance range from Rs. 850 to Rs. 8,650.

\section{Selection of Providers into the Study}

The set of providers included in the experiment was selected in three stages. In the first stage, we identified the potential universe of private providers who offer obstetric care in rural areas in Karnataka. Using 2001 census GIS data from the Government of Karnataka, we generated an initial list of hoblis (geographic areas similar to rural towns) where there was no large public health provider such as a District Hospital, Taluk Hospital, Sub-Divisional Hospital, Community Health Center (CHC), or a fully staffed functional 24/7 Primary Health Center (PHC). Note that this process eliminated all hoblis in urban areas. For all hoblis meeting these criteria, we developed GIS maps of all villages within a $10 \mathrm{~km}$ radius of each hobli, using the 2001 census GIS data from the Government of Karnataka. A survey team appointed by the Government of Karnataka visited each of the hoblis and, through interviews with local key informants such as local health workers, identified all formal private medical providers who provide obstetric care. If no such providers were identified in a study hobli, the investigators expanded the search to the rest of the taluk, including to hoblis that have CHCs, well-functioning 24/7 PHCs, or taluk hospitals. 319 potential providers were identified using this method and data on potentially eligible providers was made available to our research team.

Among the 319 providers, 280 were identified as potentially eligible for participation in the study based on the size of their catchment area, number of other potentially eligible providers nearby, number of deliveries conducted per month, and proximity to district headquarters. These 280 providers were contacted and interviewed by a survey team retained by Government of Karnataka between October 2012 and January 2013 to collect preliminary information about providers, the volume of deliveries they conduct, and obstetric services they provide, in order to further refine the list of eligible providers.

In the second stage, based on the results from the baseline provider data collection financed by the Government of Karnataka, 72 providers were dropped from the sample of 280 private obstetric because they stopped conducting deliveries, provided obstetric care services rarely or irregularly, or moved out of the area. The remaining 208 private obstetric care providers were randomized to receive one of the two types of incentive agreements or into the control arm.

In the third stage, our field team verified the eligibility of providers by visiting each of the 208 providers. During this process, we excluded 35 providers who were ineligible (fewer than 2 deliveries in the last month and fewer than 24 deliveries in the last year; stopped conducting deliveries; those who practiced at large multi-specialty hospitals or in urban areas that were included in error in stage 1). An additional 19 providers who were no longer interested in participating were also dropped. We added 21 additional providers who were found to be eligible through snowball sampling, but were not identified in the first stage. Agreements were signed with 175 providers between February and April 2013. Over the course of the study (up through mid-November), an 
additional 10 providers declined to participate or were found ineligible (e.g., because the provider changed work location or stopped conducting deliveries). Our final sample before household level data collection began was 164 providers, with 47 in the input arm, 60 in the output arm, and 57 in the control arm. 19 percent of these providers have a BAMS degree and over 70 percent have at least an MBBS.

\section{Randomization}

Providers in the sampling frame were allocated to each of the three experimental arms using simple randomization. To account for new providers identified during the third stage, an additional 200 placeholders with unique ids were also allocated through simple randomization at the same time. New providers were assigned the next available unique ID and corresponding treatment arm as they were identified in the field.

\section{Intervention Design \& Data Collection}

\section{Baseline Provider Visit: October 2012 - January 2013}

From October 2012 through January 2013, a study team organized by the Government of Karnataka visited all providers and conducted baseline interviews with each provider and one staff member at her facility to learn about her current medical practices, expectations about the performance of the average doctor in rural Karnataka, training, job satisfaction, perceived market share, and the facility's capacities, staffing, and provider demographics. Only providers in the original sample were included in this visit.

First Provider Intervention Visit: February - April 2013

Beginning in mid-February through April 2013, our field team met with all 229 providers (208 from the original sample plus the additional 21 providers identified in the third stage of provider selection) in the study to introduce the contracts, provide educational resources, and interview each provider about her expectations of her own and the average rural Karnataka doctor's current performance and ability to improve through a closedended survey. All providers received the same educational resources and were asked the same survey questions, apart from a few that were specific to the assigned contract. Additionally, new providers (those identified through snowballing) and one of their staff members participated in a brief survey with a subset of the questions asked in the baseline interviews of the providers in the original sample.

The field team was trained to administer the visit in the same order at each visit and to verify that the provider understood the contract, including, for treatment groups, that the provider had the potential to earn approximately Rs. 150,000 (about $\$ 2,700$ at the time of the contract, equivalent to more than 15 percent of a mid-level doctor's salary and more than double the state per capita income ${ }^{5}$ ) in reward payments and that any evidence of refusal to treat high-risk patients would result in an immediate termination of the contract with no further payments. Additionally, they were instructed to prepare to discuss what

5 "Karnataka" 
kinds of changes they could make to improve their own performance for when the field team returned in a few months.

Providers were given Rs. 2,500 immediately after the first visit for their time and for participating in the study, and instructed that they would receive Rs. 2,500 at each of the two main subsequent visits. The entire visit took about one hour.

\section{Second Provider Intervention Visit: May - August 2013}

From mid-May to mid-August 2013, the field team returned to all providers to follow up and learn about what kinds of strategies each provider had adopted or was planning to adopt in order to improve her own performance. They also administered short questionnaires to each provider to measure provider risk aversion, learn about current medical practices, extent of job training, job satisfaction, and perception of market share. Administrators also participated in a one of three randomly assigned questionnaires covering facility capacities and practices (random assignment of these questionnaires was independent of treatment status). Finally, the field team discussed with each provider feasible strategies for gathering the provider's comprehensive patient list of women who deliver in her facility over the next four-six months. All providers were offered Rs. 2,500 for their time and continued participation.

\section{Household Surveys of Women: December 2013 - April 2014}

Beginning in December 2013 through April 2014, at least 25 women from each provider's patient list ${ }^{6}$ who have recently given birth at the provider's facility will be interviewed with a comprehensive closed-ended survey that covers a range of topics, including questions that allow us to measure adverse health outcomes and the quality of care that each woman has received. Questions used for identifying health outcomes and quality of care were generally chosen in order to (1) match with questions previously validated in the literature as useful measures given limitations in women's recall and ability to observe and understand what is happening during labor and delivery, or (2) match with questions identified in a validation study in June - July 2011 among women in rural Karnataka, where women's answers $7-14$ days after delivery were compared to the observations of a trained observer present through her entire delivery. The household survey is expected to take about one hour and will be administered $7-20$ days after delivery. A shortened version will be administered in cases where the baby or mother has died.

In addition to the 25 women interviewed from each provider's patient list, an additional 110 women who have recently given birth will be interviewed $7-20$ days post-delivery in each provider's cluster ${ }^{7}$, a geographical area formed by asking from which villages each provider receives patients during the baseline provider interview, or the closest 35 villages, whichever is smaller. These women are identified through interviews with key

\footnotetext{
${ }^{6}$ During the second provider intervention visit, the field team developed a feasible strategy for transmitting each provider's patient list every 10 days to the field team.

${ }^{7}$ Because some providers are located close to one another, there are a total of 99 clusters covering the 164 providers in the study.
} 
informants (typically ASHA or other health workers) in each cluster. In all, about 14,990 women will be interviewed.

All women who were interviewed using the main household instrument will also be interviewed at least 28 days after delivery with a very brief instrument that will allow us to calculate 28-day infant mortality. This interview is expected to take no more than ten minutes.

Third Provider Intervention Visit: June 2014

In June 2014, the field team will return to all participating providers. All providers will be offered a final Rs. 2,500 participation payment and will be interviewed by the study team. Treatment providers will be given their one-time reward payment corresponding to their performance level over the study period.

\section{Empirical Strategy}

\section{General Econometric Framework}




\section{Individual Level}

In order to estimate the treatment effects of the intervention we plan to regress outcomes related to each hypothesis on dummy variables indicating treatment status. For patientlevel outcomes we will use the following specification:

$$
y_{i p}=\alpha+\beta_{p} T_{p}+u_{i p}
$$

where $y_{i p}$ is the outcome of interest for woman $i$ who has received care from provider $p$, and $T_{p}$ is a vector of treatment indicators. In the event that there is a lack of balance on time-invariant covariates, we will control for these in equations (1).

In a second specification, we will add additional covariates to the baseline model:

$$
y_{i p}=\alpha+\beta_{p} T_{p}+\theta X_{p}+s_{d}+\lambda_{e}+u_{i p}
$$

where $X_{p}$ is a vector of baseline (pre-contract) provider characteristics, $s_{d}$ are district level fixed effects, and $\lambda_{e}$ are enumerator fixed effects. While the inclusion of these covariates will not change the coefficient of interest (given correctly-implemented randomization), doing so may improve precision. Because we did not conduct a pilot study and suitable data is not otherwise available, we know little about this potential gain in precision a priori.

Additionally, because any improvement in provider quality induced by our interventions may alter demand for an obstetrician's services and the composition of her patients, we will include patient level covariates to assess the sensitivity of our key estimates of interest. ${ }^{8}$ In order to get a more accurate assessment of the providers' response to treatment, we will estimate:

$$
y_{i p}=\alpha+\beta_{p} T_{p}+\theta X_{p}+\gamma Z_{i}+s_{d}+\lambda_{e}+u_{i p}
$$

where everything is the same as in (2), apart from the additional inclusion of $Z_{i}$, a vector of time-invariant household characteristics (such as mother's age, education status, religion and birth history). All errors are clustered at the provider level.

We plan to implement a similar strategy for individual analysis at the cluster populationlevel (rather than just the patient-list) sample:

$$
y_{i c}=\alpha+\beta_{c} T_{c}+u_{i c}
$$

where $y_{i c}$ is the outcome of interest for woman $i$ who has received care in cluster $c$, and $T_{C}$ is a vector of dummy variables for each treatment arm and interactions among them in

\footnotetext{
${ }^{8}$ We will follow Altonji, et al. (2005) to assess the sensitivity of our estimates to different covariates.
} 
cluster $c$ (the cluster's treatment is based on the treatment of each study provider in the cluster; each cluster has one to six providers, with 92 percent having three or fewer).

In a second specification using the cluster population-level sample, we include additional covariates:

$$
y_{i c}=\alpha+\beta_{c} T_{c}+\theta X_{p}+\delta W_{c}+\gamma Z_{i}+s_{d}+\lambda_{e}+u_{i c}
$$

where $X_{p}$ is a vector of baseline (pre-contract) provider characteristics, $W_{\mathrm{c}}$ is a vector of time-invariant cluster characteristics (such as urban status, population), $Z_{i}$ is a vector of time-invariant household characteristics (such as mother's age, education status, religion and birth history), $s_{d}$ are district level fixed effects, and $\lambda_{e}$ are enumerator fixed effects. All errors are clustered at the cluster level.

\section{Provider Level}

A final approach will look at treatment effects at the provider level. For this approach, we will use the following specification:

$$
y_{p}=\alpha+\beta_{p} T_{p}+u_{p}
$$

where $y_{p}$ is the outcome for provider $p$ and $T_{p}$ is a vector of treatment indicators. In the event that there is a lack of balance on time-invariant covariates, we will control for these in equation (6).

We will also extend this specification to include covariates:

$$
y_{p}=\alpha+\beta_{p} T_{p}+\theta X_{p}+\delta W_{c}+s_{d}+u_{p}
$$

where are all variables are similarly defined.

Finally, following the logic for specification (3) at the individual level, we will also extend the specification to:

$$
y_{p}=\alpha+\beta_{p} T_{p}+\theta X_{p}+\kappa V_{p}+\delta W_{c}+s_{d}+u_{p}
$$

where $V_{p}$ are provider-level averages of their own patients' characteristics.

\section{Standard Errors}

Inference will be conducted clustering the standard errors at the provider level unless specified otherwise and using the cluster-corrected Huber-White estimator.

\section{Power calculations}

Power calculations were conducted prior to the trial. Estimated baseline performance rates and feasible improvement levels were determined using existing data from government surveys and calibrated through piloting with doctors in Karnataka and Delhi 
to ensure that they were locally appropriate. (Each of these enters into the contracts as "baseline" and "target" performance level.)

For all specifications at the individual level, we assume an intra-class correlation coefficient of 0.05 and that there are 25 individuals per provider. At the individual level, all five categories for quality of care have at least 85 percent power to detect improvements that reach the target levels, with the "Childbirth Care", "Postnatal Maternal Care", and "Postnatal Newborn Care" categories having at least 95 percent power. Two of the four outputs, post-partum hemorrhage and pre-eclampsia have at least 85 percent power to detect improvements to the target levels.

Note that these calculations do not take into account additional precision gained by including covariates.

\section{Multiple Outcomes}

For each hypothesis, we will report a mean index, which combines the information of closely inter-related outcomes. We will compute this index as in Anderson 2008 (section 3.2.1) and report its associated p-value. ${ }^{9}$ The individual outcomes that are part of the index (part of the same hypothesis) are defined in the "Hypothesis and Indicators" section below. We will also report the results for individual outcomes. In addition to normal pvalues we will also report p-values adjusted for multiple comparisons within the hypothesis so as to control the Familywise Error Rate Control (using the free step-down resampling method as in Westfall and Young 1993). For hypotheses regarding heterogeneity in response, we will treat each variable as a separate hypothesis (i.e. tests for heterogeneous effects will not be adjusted).

\footnotetext{
${ }^{9}$ The procedure suggested increases efficiency by ensuring that outcomes that are highly correlated with each other receive less weight.
} 


\section{Hypotheses}

Main hypotheses are presented below. ${ }^{10}$ Each of the specifications (equations 1- 6) above will be estimated using the indicators associated with the listed dependent variables, with coefficients of interest appearing in the third column below. Specific details about how each indicator will be measured are presented in the appendix. For regressions at the provider level (equations $6-7$ ), individual (respondent) level indicators are averaged across all women interviewed from the provider's patient list.

\section{Primary Hypotheses (eq. 1 - 5)}

\begin{tabular}{|c|c|c|}
\hline Dependent Variables & Indicators: & $\begin{array}{l}\text { Hypothesized } \\
\text { Relationships }\end{array}$ \\
\hline \multirow{3}{*}{$\begin{array}{l}\text { Maternal morbidity and } \\
\text { neonatal mortality } \\
\text { primarily influenced by } \\
\text { care before time of } \\
\text { delivery }\end{array}$} & \multirow{3}{*}{$\begin{array}{ll}\text { i. } & \text { Respondent has pre-eclampsia } \\
\text { ii. Respondent's baby is stillborn }\end{array}$} & $\mathrm{PH} 1: \beta_{O}<\beta_{C}$ \\
\hline & & PH2: $\beta_{I}<\beta_{C}$ \\
\hline & & PH3: $\beta_{O}=\beta_{I}$ \\
\hline \multirow{3}{*}{$\begin{array}{l}\text { Maternal morbidity and } \\
\text { neonatal mortality } \\
\text { primarily influenced by } \\
\text { care at time of delivery }\end{array}$} & \multirow{3}{*}{$\begin{array}{l}\text { i. Respondent has postpartum } \\
\text { hemorrhage } \\
\text { ii. Respondent has sepsis } \\
\text { iii. Respondent's baby is born alive, } \\
\text { but later dies } \\
\text { iv. Respondent's baby is stillborn or } \\
\text { is born alive, but later dies }{ }^{12}\end{array}$} & $\mathrm{PH} 4: \beta_{O}<\beta_{C}$ \\
\hline & & PH5: $\beta_{I}<\beta_{C}$ \\
\hline & & PH6: $\beta_{O}=\beta_{I}$ \\
\hline \multirow{3}{*}{$\begin{array}{l}\text { Quality of obstetric and } \\
\text { newborn care } \\
\text { primarily influenced by } \\
\text { care before time of } \\
\text { delivery }\end{array}$} & \multirow{3}{*}{$\begin{array}{l}\text { i. Respondent has high quality } \\
\text { Pregnancy Care }\end{array}$} & $\mathrm{PH} 7: \beta_{O}>\beta_{C}$ \\
\hline & & PH8: $\beta_{I}>\beta_{C}$ \\
\hline & & PH9: $\beta_{O}=\beta_{I}$ \\
\hline \multirow{3}{*}{$\begin{array}{l}\text { Quality of obstetric and } \\
\text { newborn care } \\
\text { primarily influenced by } \\
\text { care at time of delivery }\end{array}$} & \multirow{3}{*}{$\begin{array}{l}\text { i. Respondent has high quality } \\
\text { Childbirth Care } \\
\text { ii. Respondent has high quality } \\
\text { Postnatal Maternal Care } \\
\text { iii. Respondent has high quality } \\
\text { Newborn Care }\end{array}$} & PH10: $\beta_{O}>\beta_{C}$ \\
\hline & & PH11: $\beta_{I}>\beta_{C}$ \\
\hline & & $\mathrm{PH} 12: \beta_{O}=\beta_{I}$ \\
\hline \multirow{3}{*}{$\begin{array}{l}\text { Quality of obstetric and } \\
\text { newborn care } \\
\text { primarily influenced by } \\
\text { care after time of delivery }\end{array}$} & \multirow{3}{*}{$\begin{array}{l}\text { i. Respondent has high quality } \\
\text { Postnatal Newborn Care }\end{array}$} & PH13: $\beta_{O}>\beta_{C}$ \\
\hline & & $\mathrm{PH} 14: \beta_{I}>\beta_{C}$ \\
\hline & & $\mathrm{PH} 15: \beta_{O}=\beta_{I}$ \\
\hline
\end{tabular}

\footnotetext{
${ }^{10}$ Note that, regardless of phrasing, all hypotheses will be tested as two tailed hypotheses.

${ }^{11} \beta_{O}$ refers to the coefficient on $T_{\text {Output }}, \beta_{I}$ refers to the coefficient on $T_{\text {Input }}$, and $\beta_{C}$ refers to the coefficient on $T_{\text {Control }}$.

12 Two measures of neonatal mortality are used in order to overcome over-reporting of stillborn deaths compared with neonatal death (where, by definition, the baby was born alive but later died).
} 


\section{Non-contracted Outcomes and Multitasking (eq. 1 - 5)}

Contracts were designed to minimize harmful multitasking; potentially affected inputs and outputs therefore are less commonly relevant, so we are likely underpowered to identify any significant effects in this section.

\begin{tabular}{|c|c|c|}
\hline Dependent Variables & Indicators: & $\begin{array}{l}\text { Hypothesized } \\
\text { Relationships } \\
\end{array}$ \\
\hline \multirow{3}{*}{$\begin{array}{l}\text { Maternal and neonatal } \\
\text { morbidity (non- } \\
\text { contracted) primarily } \\
\text { influenced by care before } \\
\text { the time of delivery }\end{array}$} & \multirow[t]{3}{*}{$\begin{array}{l}\text { i. Respondent's baby is } \\
\text { underweight }\end{array}$} & $\mathrm{NC} 1: \beta_{O}<\beta_{C}$ \\
\hline & & $\mathrm{NC} 2: \beta_{I}<\beta_{C}$ \\
\hline & & NC3: $\beta_{O}=\beta_{I}$ \\
\hline \multirow{3}{*}{$\begin{array}{l}\text { Maternal and neonatal } \\
\text { morbidity (non- } \\
\text { contracted) primarily } \\
\text { influenced by care at time } \\
\text { of delivery }\end{array}$} & \multirow{3}{*}{$\begin{array}{ll}\text { i. } & \text { Respondent has fistula } \\
\text { ii. } & \text { Respondent has dystocia }\end{array}$} & NC4: $\beta_{O}<\beta_{C}$ \\
\hline & & NC5: $\beta_{I}<\beta_{C}$ \\
\hline & & NC6: $\beta_{O}=\beta_{I}$ \\
\hline \multirow{3}{*}{$\begin{array}{l}\text { Maternal and neonatal } \\
\text { morbidity (non- } \\
\text { contracted) primarily } \\
\text { influenced by care after } \\
\text { the time of delivery }\end{array}$} & \multirow[t]{3}{*}{$\begin{array}{l}\text { i. } \begin{array}{l}\text { Respondent has postnatal } \\
\text { depression }\end{array}\end{array}$} & NC7: $\beta_{O}>\beta_{C}$ \\
\hline & & NC8: $\beta_{I}>\beta_{C}$ \\
\hline & & NC9: $\beta_{O}=\beta_{I}$ \\
\hline \multirow{2}{*}{$\begin{array}{l}\text { Quality of obstetric and } \\
\text { newborn care (non- } \\
\text { contracted) }\end{array}$} & \multirow{2}{*}{$\begin{array}{l}\text { i. } \text { Respondent's newborn receives } \\
\text { high quality care for jaundice } \\
\text { (where appropriate) }\end{array}$} & $\begin{array}{l}\text { NC10: } \beta_{O}>\beta_{C} \\
\text { NC11: } \beta_{I}>\beta_{C}\end{array}$ \\
\hline & & $\mathrm{NC} 12: \beta_{O}=\beta_{I}$ \\
\hline \multirow[t]{3}{*}{ Maternal Mortality } & \multirow{3}{*}{$\begin{array}{l}\text { i. Respondent passed away within } \\
28 \text { days of delivery }\end{array}$} & NC13: $\beta_{O}>\beta_{C}$ \\
\hline & & NC14: $\beta_{I}>\beta_{C}$ \\
\hline & & NC15: $\beta_{O}=\beta_{I}$ \\
\hline
\end{tabular}

\section{Provider Level Demand Responses ${ }^{13}$ (eq. 6 - 7)}

\begin{tabular}{|l|r|l|}
\hline Dependent Variables & Indicators: & $\begin{array}{l}\text { Hypothesized } \\
\text { Relationships }\end{array}$ \\
\hline $\begin{array}{l}\text { Provider's patient } \\
\text { volume/market share }\end{array}$ & $\begin{array}{l}\text { i. } \begin{array}{l}\text { Number of patients on provider's } \\
\text { patient list }\end{array} \\
\text { ii. } \begin{array}{l}\text { Percent of } 110 \text { surveyed women } \\
\text { from local area around each } \\
\text { provider who went to the } \\
\text { provider for care }\end{array}\end{array}$ & PR2: $\beta_{O}=\beta_{C}$ \\
\cline { 3 - 4 } & i. Pregnancy history & PR3: $\beta_{I}=\beta_{O}$ \\
\hline Provider's patient & \multicolumn{2}{|l}{ PR4: $\beta_{O}=\beta_{C}$} \\
\hline
\end{tabular}

${ }^{13}$ Note that we do not anticipate having sufficient power to identify these effects. 


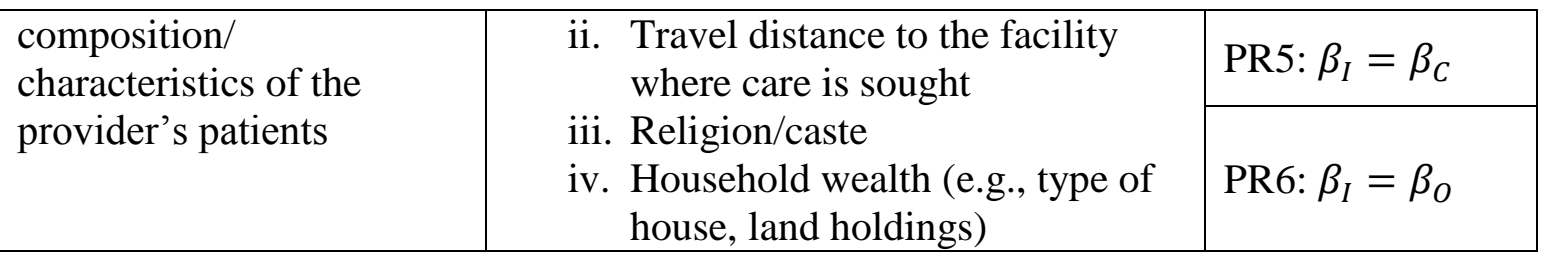

\section{Population Level Demand Responses (eq. 4 - 5)}

\begin{tabular}{|c|c|c|}
\hline Dependent Variables & Indicators: & $\begin{array}{l}\text { Hypothesized } \\
\text { Relationships }\end{array}$ \\
\hline \multirow[t]{3}{*}{ Prenatal care seeking } & \multirow{3}{*}{$\begin{array}{ll}\text { i. } & \text { Respondent received any } \\
\text { prenatal care } \\
\text { ii. } \\
\text { Respondent received prenatal } \\
\text { care from a trained provider }\end{array}$} & POP1: $\beta_{O}=\beta_{C}$ \\
\hline & & POP2: $\beta_{I}=\beta_{C}$ \\
\hline & & POP3: $\beta_{I}=\beta_{O}$ \\
\hline \multirow[t]{3}{*}{ Delivery care seeking } & \multirow{3}{*}{$\begin{array}{l}\text { i. Respondent delivers at a health } \\
\text { facility } \\
\text { ii. Respondent receives care from a } \\
\text { skilled attendant at delivery }\end{array}$} & POP4: $\beta_{O}=\beta_{C}$ \\
\hline & & POP5: $\beta_{I}=\beta_{C}$ \\
\hline & & POP6: $\beta_{I}=\beta_{O}$ \\
\hline \multirow[t]{3}{*}{ Postnatal care seeking } & \multirow{3}{*}{$\begin{array}{ll}\text { i. } & \text { Respondent received any } \\
\text { postnatal care } \\
\text { ii. } \\
\text { Respondent received postnatal } \\
\text { care from a trained provider }\end{array}$} & POP7: $\beta_{O}=\beta_{C}$ \\
\hline & & POP7: $\beta_{I}=\beta_{C}$ \\
\hline & & POP9: $\beta_{I}=\beta_{O}$ \\
\hline
\end{tabular}

\section{Mechanism Hypotheses (eq. 6 - 8)}

\begin{tabular}{|c|c|c|}
\hline Dependent Variables & Indicators: & $\begin{array}{l}\text { Hypothesized } \\
\text { Relationships }\end{array}$ \\
\hline \multirow{3}{*}{$\begin{array}{l}\text { Training for provider and } \\
\text { support staff }\end{array}$} & \multirow[t]{3}{*}{ i. $\quad$ Training for staff and provider } & MH1: $\beta_{O}>\beta_{C}$ \\
\hline & & MH2: $\beta_{I}>\beta_{C}$ \\
\hline & & MH3: $\beta_{I}=\beta_{O}$ \\
\hline \multirow{3}{*}{$\begin{array}{l}\text { Devotion of financial and } \\
\text { non-financial resources to } \\
\text { patient care }\end{array}$} & \multirow{3}{*}{$\begin{array}{l}\text { i. Facility equipment } \\
\text { ii. Facility capacity } \\
\text { iii. Time provider or other health } \\
\text { worker spends caring for } \\
\text { patients/newborns }\end{array}$} & MH4: $\beta_{O}>\beta_{C}$ \\
\hline & & MH5: $\beta_{I}>\beta_{C}$ \\
\hline & & MH6: $\beta_{I}=\beta_{O}$ \\
\hline \multirow[t]{3}{*}{ Staffing types/levels } & \multirow{3}{*}{$\begin{array}{l}\text { i. Qualifications of staff } \\
\text { ii. Number of staff members }\end{array}$} & MH7: $\beta_{O}>\beta_{C}$ \\
\hline & & MH8: $\beta_{I}>\beta_{C}$ \\
\hline & & MH9: $\beta_{I}=\beta_{O}$ \\
\hline \multirow[t]{3}{*}{ Administrative procedures } & \multirow{3}{*}{$\begin{array}{l}\text { i. Staff payment structure } \\
\text { ii. Referral patterns } \\
\text { iii. Patient tracking } \\
\text { iv. Patient follow-ups }\end{array}$} & MH10: $\beta_{O}>\beta_{C}$ \\
\hline & & $\mathrm{MH} 11: \beta_{I}>\beta_{C}$ \\
\hline & & $\mathrm{MH} 12: \beta_{I}=\beta_{O}$ \\
\hline \multirow[t]{3}{*}{ Provider effort } & \multirow{3}{*}{$\begin{array}{l}\text { i. Hours/week present in facility } \\
\text { ii. Days/week present in facility } \\
\text { iii. Time spent caring for personally } \\
\text { patients/newborns }\end{array}$} & MH13: $\beta_{O}>\beta_{C}$ \\
\hline & & MH14: $\beta_{I}>\beta_{C}$ \\
\hline & & $\mathrm{MH} 15: \beta_{I}=\beta_{O}$ \\
\hline
\end{tabular}




\begin{tabular}{|c|c|c|}
\hline \multirow{3}{*}{$\begin{array}{l}\text { Outreach and information } \\
\text { campaigns }\end{array}$} & \multirow{3}{*}{$\begin{array}{l}\text { i. Sources of relevant information } \\
\text { for women in the community } \\
\text { ii. Women's rationale for delivery } \\
\text { location }\end{array}$} & MH16: $\beta_{O}>\beta_{C}$ \\
\hline & & MH17: $\beta_{I}>\beta_{C}$ \\
\hline & & MH18: $\beta_{I}=\beta_{O}$ \\
\hline \multirow{2}{*}{$\begin{array}{l}\text { Expenditures within the } \\
\text { facility }\end{array}$} & \multirow{2}{*}{$\begin{array}{l}\text { i. Resource allocation } \\
\text { ii. Time allocation }\end{array}$} & MH19: $\beta_{O}>\beta_{C}$ \\
\hline & & $\begin{array}{l}\text { MH20: } \beta_{I}>\beta_{C} \\
\text { MH21: } \beta_{I}=\beta_{O}\end{array}$ \\
\hline \multirow[t]{3}{*}{ Knowledge } & \multirow{3}{*}{$\begin{array}{l}\text { i. Vignette performance } \\
\text { ii. Recommendations }\end{array}$} & MH22: $\beta_{O}=\beta_{C}$ \\
\hline & & MH23: $\beta_{I}=\beta_{C}$ \\
\hline & & MH24: $\beta_{I}=\beta_{O}$ \\
\hline \multirow[t]{3}{*}{ Fees for services } & \multirow{3}{*}{$\begin{array}{l}\text { i. Normal fees for standard } \\
\text { prenatal care } \\
\text { ii. Normal fees for vaginal delivery } \\
\text { iii. Normal fees for C-section } \\
\text { delivery }\end{array}$} & $\mathrm{MH} 25: \beta_{O}=\beta_{C}$ \\
\hline & & MH26: $\beta_{I}=\beta_{C}$ \\
\hline & & MH27: $\beta_{I}=\beta_{O}$ \\
\hline \multirow{3}{*}{$\begin{array}{l}\text { Provider plans/strategies } \\
\text { for improvement }\end{array}$} & \multirow{3}{*}{$\begin{array}{l}\text { i. Provider's stated strategies for } \\
\text { making improvements, both } \\
\text { planned and executed }\end{array}$} & HET7: $\beta_{O}=\beta_{C}$ \\
\hline & & HET8: $\beta_{I}=\beta_{C}$ \\
\hline & & HET9: $\beta_{I}=\beta_{O}$ \\
\hline
\end{tabular}

\section{Heterogeneity (eq. 1-3, 6-8)}

Each of the following indicators will be entered as an interaction term with treatment status in order to test for heterogeneous responses.

\begin{tabular}{|c|c|c|}
\hline Heterogeneity & Indicators: & $\begin{array}{l}\text { Hypothesized } \\
\text { Relationships }\end{array}$ \\
\hline \multirow{3}{*}{$\begin{array}{l}\text { Subjective expectations } \\
\text { about performance }\end{array}$} & \multirow{3}{*}{$\begin{array}{l}\text { i. Provider's beliefs about baseline } \\
\text { performance in inputs } \\
\text { ii. Provider's beliefs about baseline } \\
\text { performance in outputs }\end{array}$} & HET1: $\beta_{O}=\beta_{C}$ \\
\hline & & HET2: $\beta_{I}=\beta_{C}$ \\
\hline & & HET3: $\beta_{I}=\beta_{O}$ \\
\hline \multirow{3}{*}{$\begin{array}{l}\text { Subjective expectations } \\
\text { about possibility of } \\
\text { improvement }\end{array}$} & \multirow{3}{*}{$\begin{array}{l}\text { i. Provider's beliefs about possible } \\
\text { improvements in inputs } \\
\text { ii. Provider's beliefs about possible } \\
\text { improvements in outputs }\end{array}$} & HET4: $\beta_{O}=\beta_{C}$ \\
\hline & & HET5: $\beta_{I}=\beta_{C}$ \\
\hline & & HET6: $\beta_{I}=\beta_{O}$ \\
\hline \multirow{3}{*}{$\begin{array}{l}\text { Provider plans/strategies } \\
\text { for improvement }\end{array}$} & \multirow{3}{*}{$\begin{array}{l}\text { ii. Provider's stated strategies for } \\
\text { making improvements, both } \\
\text { planned and executed }\end{array}$} & HET7: $\beta_{O}=\beta_{C}$ \\
\hline & & HET8: $\beta_{I}=\beta_{C}$ \\
\hline & & HET9: $\beta_{I}=\beta_{O}$ \\
\hline \multirow[t]{3}{*}{ Job satisfaction } & \multirow{3}{*}{$\begin{array}{l}\text { iii. Index of satisfaction based on } \\
\text { answers to } 13 \text { likert-scale } \\
\text { questions }\end{array}$} & HET10: $\beta_{O}=\beta_{C}$ \\
\hline & & HET11: $\beta_{I}=\beta_{C}$ \\
\hline & & HET12: $\beta_{I}=\beta_{O}$ \\
\hline \multirow[t]{3}{*}{ Risk aversion } & \multirow{3}{*}{$\begin{array}{l}\text { i. } \begin{array}{l}\text { Coefficient of risk aversion } \\
\text { based on hypothetical lotteries }\end{array}\end{array}$} & HET10: $\beta_{O}=\beta_{C}$ \\
\hline & & HET11: $\beta_{I}=\beta_{C}$ \\
\hline & & HET12: $\beta_{I}=\beta_{O}$ \\
\hline
\end{tabular}




\begin{tabular}{|l|l|l|}
\hline Provider characteristics & $\begin{array}{l}\text { i. Gender } \\
\text { ii. Age } \\
\text { iii. Qualifications } \\
\text { iv. Personality } \\
\text { v. Intelligence } \\
\text { vi. Personality*Intelligence }\end{array}$ & HET13: $\beta_{O}=\beta_{C}$ \\
\cline { 3 - 3 } & \multicolumn{2}{|l}{ HET15: $\beta_{I}=\beta_{C}$} \\
\hline
\end{tabular}




\section{References}

ALTONJI, Joseph G., Todd E. ELDER, and Christopher R. TABER. "Selection on observed and unobserved variables: Assessing the effectiveness of Catholic schools." Journal of political economy 113.1 (2005): 151-184.

"Karnataka." Www.ibef.org. India Brand Equity Foundation, Nov. 2010. Web. <http://www.ibef.org/download/Karnataka_190111.pdf>.

"WHO Recommended Interventions for Improving Maternal and Newborn Health." World Health Organization, 2009. Web.

<http://whqlibdoc.who.int/hq/2007/WHO_MPS_07.05_eng.pdf>. 